\title{
Using Text with Pictures in Primary School to Improve Reading Comprehension for Hearing Impaired Students
}

\author{
Abdul Rahim Razalli, Renate Olga Thomas, Nordin Mamat, Noreha Yusuf \\ Universiti Pendidikan Sultan Idris, Perak, Malaysia \\ E-mail: Rahim.r@fpm.upsi.edu.my
}

\begin{abstract}
The objectives of the study are to determine whether using text with pictures is effective to improve reading comprehension for students with hearing impairment, to examine other strategies that can support the development or improvement of reading comprehension for students with hearing impairment and to determine the factors affecting reading comprehension for students with hearing impairment. A qualitative research design was chosen to answer three research questions. Two sets of instruments (observational checklist and interview questionnaires) have been used to obtain information of reading comprehension and factors that influence it. Six hearing impaired students and five teachers were selected as the respondents through purposive sampling technique. The findings show that text with pictures can help to improve reading comprehension for students with hearing impairment. The implications of this study show that text with pictures motivate students with hearing impairment to read and it have to be encouraged in primary school. A more comprehensive study should be undertaken for higher order thinking skills and the use of interactive models for reading comprehension lessons for students with hearing impairment.skills are across all subjects.
\end{abstract}

Keywords: reading comprehension, hearing impaired students, reading factors and reaching strategies

Hearing impaired (HI) students same as the hearing students, they must understand passages, stories and sentences from various school subjects. All students should be able to make a distinction of the important facts and ideas from words they are reading and recognizing words that are unimportant. At times this remains difficult for hearing impaired students for the reason that, they are reading words or sentences they cannot comprehend. Reading is a dual progress whereby one part is the aptitude to decode print and know what one is reading and another part is reading comprehension and without it, one is not truly reading (Bickham, 2015). Among students, these skills are highly related but there are some populations of children who struggle with the skills necessary to either decode or comprehend. In other words, when most children learn to read, hey either develop the skills to both decode and comprehend or they do not. Yet there are students who are capable decoders but still perform poorly on measures of reading comprehension because they are not making the necessary connections between words as they form sentences, paragraphs and entire texts. The inability to understand the meanings of words cause problems for comprehension. Effectively teaching students to read and write well in English and mother tongue is an important responsibility in today's primary schools. It can be said that a child who is accomplishing well on measures of reading comprehension is by default a satisfactory decoder, since without knowing the words it is difficult to comprehend the message on paper. Reading comprehension is a serious skill that is needed for attainment in school and beyond, yet many students are reading below grade level. Research has shown that poor reading ability has been associated with poor school performance in general, behavioral problems and poor mental health. This makes a strong case for the reading comprehension strategies for hearing impaired students. The term hearing impaired (HI) is one that is used frequently and it is regarded as a condition whereby a person is unable to hear.

The language of a hearing impaired person is normally considered below that of a hearing person of the similar age as well as experiences. Most of the hearing impaired students have reading difficulty (Bickham, 2015). In order to improve reading comprehension for hearing impaired students, making words memorable by using visual aid which includes text with pictures, can be vital because it reduces the amount of practice required to get the words into students' reading vocabulary. Words must have connected meanings, making the connections explicit help students remember the words which will increase their vocabulary and reading skill. As we all know that the eyes of the hearing impaired people are their ears, because they cannot hear and they mostly depend on what they see since they are visual oriented people. In order for them to learn or improve their reading, visual aid such as text with pictures should be used, because words cannot be presented or used in isolation, they need to be used in a meaningful context (Durkin, 
2014). To allocate meaning to texts, readers depend on previously kept knowledge, the domain and specific knowledge about different text structure and types (Kamhi \& Catts, 2012).

Basic literacy which includes reading has been always important to lives ofhearing impaired people. Reading is a skill that help hearing impaired people to use auto teller machines, read fast food menus, surf the internet as well as read newspapers, use their hand phone to chat and able to read the captioned on TV when watching, furthermore, their living is reliant on literacy, mostly reading and writing, however, technology is quickening this dependency. Currently, the ability to read is more vital than ever. It is necessary for succeeding in school, becoming an educated citizen with a bright future or career, and be able to experience an individual fulfilment. Hearing impaired students face challenges in many areas that are serious for a prosperous reading comprehension. Moreover, sometimes teachers emphasize reading skills slowly instead of boosting the development of strategic thinking and problem solving in connection with reading. As a result, students battle with reading because of a weak foundation of first language (sign language). As we all know that education begins from home, thus parents play a role in the education of their children. Past research indicates that on average, hearing impaired students at the age of eighteen they are leaving high school but their reading level is said to have reached only a third grade to fourth grade reading level, and over 30 percent of them leave school functionally by the old standard (Lederberg et al., 2013). This compares to a functional illiteracy rate of less than 1 percent among their hearing peers. Children with hearing impairments have educational and perceptive insufficient or progressive delays due to language problems. Some children suffer from discrimination and lack of social because of the communication difficulties. Reading is getting the meaning or gist of a text. The reader moves from recognizing letters to comprehending a word, sentence or passage and holds this information in memory as he or she moves on to comprehending more print. Reading comprehension is considered the heart of reading (Durkin, 2014) the actual core as well as depth of reading. Indeed, it is the fundamental purpose of reading. Reading comprehension is known as the lively process of making meaning from the text, it includes retrieving prior knowledge, understanding vocabulary plus concepts, making inferences, and connecting key ideas. For a person to comprehend or understand what they read, they need to set objectives for reading, relate their knowledge and experiences to the text, read words and phrases fluently, use approaches and assistance to construct meaning during and after reading, familiarize approaches that match the text and their objectives, uphold task perseverance, know the author's purpose, differentiate between truths and untruths, and come up with analytical conclusion.

Reading and writing is not something new in the field of Deaf Education. This has been happening since the time of Laurent Clerc and Thomas Gallaudet opened the first school for deaf children in the United States back in 1817, and instruction methods concerning to reading and writing have always been a main goal in teacher training programs. Yet, an average of deaf children is leaving school with a reading level that hovers around the fourth-grade level (Gallaudet Research Institute, 2016). Hearing impaired students uses the same curriculum as the other hearing students; however their instructions are given in different ways such as by using sign language and visual aids. They learn what other students learn in school that's why they can be found in integrated or in an inclusive school's programme. Hearing impaired students show different types of reading difficulties, such as word recognition, decoding, sentence-level processing, and text comprehension. Written text and visual aid are some strategies that can be used for students to read.

Hearing impaired students struggle to acquire skills needed to become confident readers and comprehend what they read. Moreover, they find it difficult to read and write mostly because of their lack of ability to phonetically break down a written word and comprehend it (Bickham, 2015). This limits and delays their ability to develop vocabulary skills and effectively reduces literacy opportunities normally available to their hearing counterparts. As we all know that a picture is worth a thousand words, however, when it comes to reading comprehension, we would say a visual display helps readers understand, organize, and remember some of the written thousand words. Stated that in order for children to prosper in both, reading skills and overall knowledge, their learning environment must be set up properly. A benefit could be by use of pictures and the written word throughout the classroom. Equally important, spoken language's knowledge and skills contribute to reading comprehension for students, unfortunately the development of reading in deaf children is usually delayed because of the difficulties they face in developing a spoken language skills and knowledge. For instance, Wauters stated that the average marks of hearing impaired children for reading comprehension were outrageously low. Children with hearing impairments at the age of 17-20 years are at the same reading level as first grade of primary education. That shows how hearing impaired children are struggling with reading comprehension and there is a need for improvement. Lack of learning strategies for reading comprehension is one of the factors that causes hearing impaired students to find it difficult to understand what they are reading. Another factor is the lack of acquiring sign language at an early age. 
Agreeing to Andrews \& Mason (2011) hearing impaired students have difficulties with lower-level skills which hinders the development of independent reading strategies. This reading problem needs to be reduced by using an effective strategy of reading comprehension. Therefore, this research intends to improve the reading comprehension skills of hearing impaired students using text with pictures. Hudson, Lane, \& Pullen (2015) stated that, a student who is incompetent to decode words correctly will be incompetent to comprehend a text. Without automaticity, a reader's slow and choppy pace inhibits their comprehension of text. The way a reader with poor prosody groups and expresses words causes' confusion. Importantly, the main objective for reading is to construct meaning from the print. However, in primary school the text have to be accompanied by pictures, in order for the students to be able to make connection of the words and the pictures and understand whatever they are reading.

Reading comprehension is necessary in languages, for people to be able to make sense of what they are reading. National Association of Educational Progress (National Assessment US, 2014) stated that a student must be able to read and understand as well as to be able to synthesize, explain, and analyze what he/ she read in order to become a proficient reader. The ability to visualize, aids both understanding of what is being read and enables the reader to identify when she is struggling to understand what she reads. Poor comprehension-monitoring has also been suggested as an area of deficit in hearing impaired students. In a study of reading habits among deaf and hearing college students, Marschark et al. (2012) found that deaf college students were more likely to report greater hours spent reading but they recognized fewer book and magazine titles compared to hearing college students. While not the focus of their study, they speculated that deaf students may read at a slower pace, spend more time understanding what they've read, and have less awareness of mistakes in comprehension compared to their hearing peers. Reading comprehension is said to be a continuing concern for students with hearing impairment (Benedict, Rivera, \& Antia, 2015) making the topic of reading comprehension extremely important. Mentioned that there is only little progress in improving description comprehension for hearing impaired readers regardless of past research, proving a need for further research into this topic. Deaf and hearing impaired students globally often struggle with reading, that also includes the hearing impaired students in Malaysia. Thus, there is a need for implementing effective reading strategies to improve reading for hearing impaired students.

The aims of this study are to determine whether using text with pictures is effective to improve reading comprehension for students with hearing impairment, examine other strategies that can support the development or improvement of reading comprehension for students with hearing Impairment an determine the factors affecting reading comprehension for students with hearing impairment.

This research combine three theories such as Learning Theories, Teaching Model and Billingual Theory. Learning theories provides directions in teaching and learning. It is usually used as a guide in education whereby positive and negative reinforcement are used appropriately to enhance learning among students. Learning theories consists of many theories, however this study focused on clay's theory of learning, social learning theory and schema theory. Clay's theory of learning to read is grounded on the knowledge that children create intellectual systems to comprehend the creation and linguistic. Preparing the reader to meet the text is the focus of instruction in the whole language instructional model based on Goodman's work. Social learning theory best fits this research because the Vygostkian position is that much of cognitive competence is learned in interaction with others, in particular with skilled adults who pass on cognitive skills and concepts.

Teaching model is essential to improve and enhance learning, teachers teaching children with hearing impaired should read and make research on teaching model that can improve the reading comprehension for their children in primary schools. Additionally, hearing impaired children struggle with various types of text and this cause difficulties for them to understand text. For instance, hearing impaired people are observed and they unable to make use of background knowledge to make meaning from the text when reading. They fail to understand that lack of background knowledge contributed to their incompetence to make meaning. The cultural impact on literacy acquisition also applies to students who are hearing impaired. In addition to this, if students who are hearing impaired are not exposed to language through sign language or other means during their early years, those student will struggle to catch up to their peers later on in their education. Discussed students becoming more engaged and having the ability to acquire meaning when an assignment is connected to that student's cultural identity. An example of connecting a student's culture to an assignment for students who are hearing impaired would be to allow them to use technology to record themselves signing an essay or a story as an assessment. If we can only acknowledge the role cultural identity plays in a student's life. Earlier studies with a related topic of reading comprehension for hearing impaired students had a different focus compared to this study because their focus was more on different strategies used to improve reading comprehension, but this study focused on the use of text with pictures to enhance reading 
comprehension, identifying strategies to improve reading comprehension and identifying factors that hinders reading comprehension for hearing impaired students.

On the other hand, bilingual theory have to be considered also in order to improve reading comprehension for students with hearing impaired. Hearing impaired students have to be viewed from their cultural perspectives when using a bilingual model. Viewing from a cultural perspective includes noticing that the spoken and signed languages are different and have to be valued equally, increasing pride and uniqueness in being hearing impaired, connecting students to deaf people or elders who can be good role models, and speaking of difficulties and struggles with cultural consciousness (Evans, Zimmer, \& Murray, 2014). To guide this study, I looked at language as a barrier that leads to poor reading comprehension. Most hearing impaired students have parents who struggle to communicate with them from early age and this lead to lack of language acquisition at early age. Children's cognitive and social skills affect their language acquisition. In turn, as children develop more language, their cognitive and social skills are changed or modified. A delay in acquiring language leads to literacy difficulties. The acquisition of a language is a normal procedure that occurs naturally for children who can hear. Language is essential in all school learning because it is used as a medium of instructions. It is also used for communication, and enables people to acquire perceptions and to improve their thinking skills. However, children with hearing impairment rarely acquire language at birth especially those with hearing parents, they only acquire language at school since their parents can not sign or do not know sign language. In short, language is a significant means of communication used by people to express their identity and draw conclusions about other people. It is also considered more attached to culture and tradition. People who speak the same language understand one another very well than with people who speak different language. On the whole, it is more difficult for students who are hearing impaired to obtain jobs after high school because of the language barrier and possible lack of literacy skills which include the reading comprehension.

\section{METHOD}

For this study, a case study was used to acquire information and help to improve reading comprehension for hearing impaired students using text with pictures. The case study was the most flexible design for this study of all the research designs because it allowed the researcher to retain the holistic characteristics of real-life events in it natural setting. It assisted in understanding the phenomena that involved many specific methodological analysis such as interviews and direct observation which are used in this research study as research instruments. Therefore, a qualitative method rather than a quantitative was favored for this research study because of the exploratory kind of research questions that were focused on. The researcher needed to study a group or population, identify variables that cannot be easily measured, or hear in silenced voices, the case study allowed the researcher to retain the holistic characteristics of real-life events in it natural setting (Creswell, 2013). Thus, a case study which is a design for qualitative research was used and the natural setting was an integrated school that comprise of mainstream classes and hearing impaired classes. This study has focused on five teachers teaching hearing impaired students and six year three students at an integrated school where hearing impaired students attend. The participants of five teachers and six students were purposively selected based on the this characteristics: teachers should be able to sign and have at least two years of teaching experiences, welleducated or qualified teacher, primary school teaching and teaches English. While, the students were selected based on some characteristics such as age range of seven to ten years, in third grade and should be hearing impaired

\section{FINDING AND DISCUSSION}

\section{Findings}

Finding from the observation showed that text with pictures can help to improve reading comprehension, this is supported by the results from the reading comprehension test, the test was taken after the students had read the text with pictures, as observed the results of the six students ranged between 8 to 10 out of 10 questions which were answered correctly, the text with pictures helped them to have a clear understanding of the text and enabled them to pass the comprehension test. During the observation students were excited to read the text with pictures and they were referring to pictures to get the sign and meaning for words that they did not know. Furthermore, the data were collected from interviews corresponding with the observed results for the use of text with pictures. Participant 1 indicates what pictures can do to students when reading "they can guess from the pictures what the story is about, even if they don't understand all the words in the text. Pictures helps them to comprehend well [T1P1M1S17D14'02]." Equally important, participant 2 reasoned that "because from the pictures they can identify about the form of comprehension. Maybe the picture is about in the classroom they can visualize the activities in the classroom for another text without the pictures they 
cannot understand or connect what the story is about [T1P2M1S18D14'02]." However, "Is better when text have pictures, is for students to understand. Pictures are very important for HI students, it help them to know what they are reading. first and foremost, you have to extract the word, know what is the picture about, understand the picture and this will help to improve the reading comprehension of pupil [T2P3H1S2D03'04]." Lastly, participant 4 said "mmh.... I think it will help to improve the reading and apart from improvement I think it will even improve the....their vocabulary the same time, because when they are reading they will have to look at the pictures and they can make...get the meaning of the pic...of the text in relation to the picture that is there [T3P4L1S8D07'04]." The analysis of the above information is that text with pictures are essential to hearing impaired students, and they can be used to improve reading comprehension. Pictures make the text to become more attractive, help symbolize characters, events and objects described in the text. Also, it displays a structured relations of the important idea in the text and it gives a clear explanation of difficult parts of the text. Moreover, it helps them to be able to guess the meaning of the text from looking at the pictures. Pictures act as an aid to understand new information and also catch the attention and interest of students. Therefore, the use of text with pictures for students with hearing impairment in primary school can help the students to extract more information and make meaning of the text.

Apart from using text with pictures there are other strategies that can be used to improve the reading comprehension for hearing impaired students. Nonetheless, various scholars have argued that only appropriate learning strategies can improve students' reading comprehension. The findings from the observation indicates some strategies used during this study such as, a method of scaffolding, the use of dictionaries during reading, the extractions of new words first before reading the text, finger spelling, memorization, re-reading and signing while reading. All the same, the collected data from the interviews indicates that different teachers uses different strategies. Participants 2 indicates that one of the strategy to improve reading is "flashcards with the sign language [T1P2M1S8D14'02]." However, participant 1 confirmed that "yes, visual aid. Use many visual aids. Now we have hand phone and we use them and show the pictures if we cannot find the real item [T1P1M1S11D14'02]." Participant 3 added that "Role-play or acting, sign exact English, use ICT and visualization [T2P3H1S11D03'04]." Participant 3 continued to explain that "Sign Exact English can improve reading comprehension because the words are accompanied by signs, each word with it sign for primary school [T2P3H1S11D03'04]."
Furthermore, participant 3 indicated that "By making use of ICTS, we now have hand phones with data from the government, so we use them in class to get pictures [T2P3H1S13D03'04]." Also participant 4 expressed that "mmh, since they are visual students, visualizations is the key aspect in their learning. So every lesson every thing in the classroom should be visual and even our teaching aid must be visual they will mmh you know be able to develop visualization... to develop that in themselves, looking at things analyze and make meaning out of it [T3P4L1S19D07'04]." Moreover, participant 5 explicit that "ummh, I think one of the things that can be used are daily news, when they tell daily news, you bring in pictures, so from the pictures they can create a story and through that story, they basically, they can start imagining and when they can imagine, they can better relate to the words because you already incorporating pictures in all these things, of role-play, I think role-play or stories as well because now you are giving them a script where there is a picture, here is a word and then they have to kind of memorize it, in order for them to be able to role-play, so role-play is also very important and deaf people are very good with story telling. [T4P5A1S12D15'04]." The above information presents the different strategies that participants stated as strategies that can be used to improve reading comprehension for students with hearing impairment such as the use of visual aids like flashcards and pictures, the use of role play, Sign Exact English, ICT and visualization. The analysis of the above information is that, there are several strategies that participants of this study mentioned, however teaching and learning strategies or even instructional tools for teaching reading can differ from one teacher to another, therefore the participants emphasized on the use of visual aids as one of the most successful strategy for reading comprehension when teaching students with hearing impairments in primary school.

During the time of collecting data the researcher observed several factors that influenced reading comprehension, such factors are; the complexity of text, it was observed that when the students are given a text that is not at their level they find it difficult to read it. In one of the observed class the students were given a text that was not at their level, the text was difficult for them and they could not read it because they did not know the vocabulary used in the text. Another factor observed was the lack of decoding, meaning students could not translate some printed text into signs, lack of vocabulary and word cognition, while two students showed anxiety during reading comprehension and it hindered their comprehension, while as for one student lacked reading motivation and interest, lastly medical problems is another factor observed like sight, one of the students struggled to read because of her sight, the text needed to be enlarge for her to be able to read 
it. However, the findings from interview correlates with the observation findings, the participants have commented further on this theme of factors affecting comprehension as follow; Participant 1 stated that "the difficulties of how to understand the word because their vocabulary of Sign language is little. He/she saw the word can spell but does not know the meaning, so we show them one by one with a picture or drawing what is that spelling mean [T1P1M1S1'14'02]." However, participant 2 added that "the difficulties of English [T1P2M1S2D14'02]." Participant 1 continued to say that "the lack of sign language, yes! First, we have to teach them what the sign language for the word is o that only we can read the comprehension, if they don't know the sign then they cannot do the reading of the comprehension [T1P1M1S3D14'02]." In addition, participant 3 stated that "Lack of vocab and laziness [T2P3H1S16D03'04]." While participant 4 expressed that "mmmh there are so many factors I think, given the fact that they might have limited materials like I said in the society to read and their community is just the school and lack of textbooks can be one of the factors and may other lack of reading materials like local newspapers and journals and other...let say like magazines maybe and if they don't have that access to go to the library it can affect the reading comprehension [T3P4L1S26D07'04]." Participant 3 continued to emphasis on "Lack of focus, lack of support from the parents [T2P3H1S17D03'04]." However, participant 4 proceed to explain that " $m m h$ the knowledge of a teacher, I mean, it influences the reading comprehension because you have to know the language and you have to know what you are doing if a

layman, if you put layman in the class definitely cannot teach the language, if you put me in grade 1 , if I don't know sign language I can't even teach the kids the basics of sign language or reading for that matter, so teachers should posses, she must be competent, qualified and have the knowledge to teach language, in this case [T3P4L1S32D07'04]."

Finally, participant 5 said "first of all, I think they lack vocabulary, they do not have the vocabulary in a sense that they don't know words. I don't know how to put it, but they lack vocabulary, I think $i$ should stick to that. there is no vocabulary, I think also, the..... through my own reading and research as well I come to the realization that they actually, the first language need to be developed, even my own experience, my mother tongue is important for me to be able to learn the second language, and second language is is ...ah... English is second language for the hearing impaired, but if the foundation of sign language is not fluently laid or if they lack vocabulary in sign language, they won't be able to produce in English right? which is the language they use for reading [T4P5A1S18D15'04]." The above information reveals that the factors that affects reading comprehension for student with hearing impairment are lack of vocabulary, if the students do not have vocabulary they won't be able to read or even understand what they are reading, late acquiring of a sign language is one factor that participants have reported about, lack of support from parents, the knowledge of parents, lack of relevant reading materials for hearing impaired students such as text with pictures and sign exact English text that can enhance reading comprehension in primary school, lack of role models, and lack of exposure to reading at an early age and the environment. The analysis of the information from the participant is that students with hearing impairment do face challenges from an early age, the main challenge be the late acquiring of sign language, lack of vocabulary and the lack of relevant reading materials for these reasons they do not perform well in reading and they find it difficult to comprehend what they are reading

\section{Discussion}

According to the information shared by the participants of this study, text with pictures prompt students with hearing impairment to read. Pictures makes the text to become more attractive, help symbolize characters, events and objects described in the text. Also, it display a structured relations of the important idea in the text and it gives a clear explanation of difficult parts of the text. These findings are related with previous researchers for instance, found out that pictures provide hearing impaired students with a scaffold that can be used to enhance their access to reading comprehension also increase their motivation for reading. Also, a study conducted by Mich, Pianta, and Mana (2013) compared stories with pictures to stories without pictures and discovered that adding pictures to a story supports the reading comprehension of students who are deaf or hard of hearing. In their findings they state that "the simplified and illustrated stories, having a higher readability index, make the comprehension exercise easier and both children groups (deaf and hearing) got the best results" (Mich et al., 2013). Based on the findings, it can be concluded that adding pictures while teaching students who are hearing impaired can enhance reading comprehension. The findings of this study and of Mich et al. (2013) support each other, in which adding pictures reinforce the reading comprehension of students. Therefore, from the analysis text with pictures is important in the primary school for hearing impaired students. However, the pictures should be colorful, appropriate and relevant for the text. Text with pictures is said to be good at motivating or inspiring to students, it makes the reading interesting and fun for primary school students. Students become more excited and involved in reading 
texts with pictures. Pictures are beneficial when connected to a text because they help students to make sense of the text (Lederberg et al., 2013). To conclude, another way to integrate pictures is to introduce them during story time. Trussell and Easterbrooks (2013) add that use of picture cards during read aloud will enhance the vocabulary and boost comprehension.

This study revealed that apart from using text with pictures, there are other strategies that can be used to successfully support the development or improvement of reading comprehension. Based on the findings of this study, the following strategies are being used in the observed integrated school to motivate, enhance and develop reading comprehension for hearing impaired students; the use of dictionaries during reading and also using the Signing Exact English (SEE) textbooks help students to understand what they are reading and motivates them to read on their own because the SEE texts consist of a text and it exact sign, such text increase self efficacy and encourage students with hearing impairment to read and comprehend what they are reading, as for the SEE textbooks and dictionary used in Malaysian schools for the hearing impaired students. Another strategy is to extract words first before reading the text, the teacher do the extraction of all the vocabulary and the students look them up in the dictionary for meaning and they focus on their signs because students can not read what they can not sign. On the other hand, according to Oakhill et al. (2009) reading strategies stipulate specific instructions to prosper comprehension skills, some other reading strategies are visualization, scaffolding, predicting, deducing, making use of flashcards, ICT, sum-up and analyzing. In addition, Vygotsky suggested that cognitive development depends on interactions between children and expert adults or parents who mediate the children's learning experiences by helping them understand their world using the tools of their culture. An important tool, in this case, is language (Vygotsky, 1978). A reading lesson is a conversation or dialogue. Teachers or parents as expert readers provide scaffolding or modelling for the child in how to figure out the meaning of text. The child then tries to read, at first with the expert reader's support. But then slowly the child takes over the reading task and reads independently (Andrew et al., 2014). The schema theory is important during reading because readers bring their background knowledge which is used for understanding and expectations to a text (An, 2013). Supporting the findings of this study, text with pictures increases the general knowledge of students. Furthermore, students can become better thinkers when they are encourage to understand what they are reading which leads to critical thinking and reasoning as a higher order thinking skills, when the instruction is intended to enhance acquisition of knowledge. The findings shows some strategies that can be used to successfully support the development or improvement of reading comprehension for students with hearing impairment such as the use of visual aid (like flash cards, pictures), role play, use of SEE textbooks and story books, use of ICT and visualizations. Teaching approaches that increase the acquisition of knowledge comprise spread out preparation (observing material over time against studying), using a range of cases for students to identify where a concept is appropriate, and exercise at recovery (repetitively memorizing material over time) with educational response. Furthermore, research showed that hearing impaired people raise up previous experience from the text for explanation and this is done through a visual-matching technique and not as a metacognitive strategy (LaSasso, 1985). Metacognitive relates to the concept of this study for improving reading comprehension, thus it can be used as a strategy or teaching model to improve reading comprehension for hearing impaired students. Teaching in metacognitive strategies is helpful for students such as hearing impaired who lack background understanding as well as reading interpreting skills (Brigham, at all, 2007). The drive of teaching metacognitive awareness is to invest students with understanding and regulate over thinking that expert readers use when reading (Benedict, Rivera \& Antia, 2015). The purpose of reading and the level of reading material plays a role in a student's life. According to previous research, all learners are able to acquire the skill of how to use metacognitive strategies in order to make meaning from text (Benedict et al., 2015)

This research identified seven factors that are affecting reading comprehension. Reading comprehension is defined as a complex process of distinguishing printed symbols and explaining the meaning of the symbols (Dennis, 2008). Thus, some of the factors affecting reading comprehension are text complexity, lack of vocabulary or decoding and lack of word recognition, environmental influences, lack of parents involvement, anxiety during reading comprehension, lack of motivation and interest, medical problems and lack of early sign language development. Therefore, in this section, these factors are discussed. One of the observed factors that affect reading comprehension for HI was the text complexity. To support this, (Andrew et al., 2014) stated that if the text is too difficult for students they won't be able to understand it content and one must have a lot of vocabulary to be able to comprehend the unknown words through applying the opinions of context. The second factor from the findings was the environmental conditions, an unorganized environment affect the reading comprehension of students than those who read in a quiet and disciplined place. The third factor was the anxiety during reading comprehension. Tests, 
exam, class work, or homework add pressure on students' comprehension than reading for pleasure. When a student is having reading anxiety it leads to not understanding instructions which leads to confusion and poor comprehension of the text. The fourth factor was lack of motivation and interest. According to An (2013), students' motivation and interest are crucial in developing reading comprehension skill. When the reading materials are interesting for students they understand it easily and remember it clearly. English teachers must motivate students by giving them interesting reading materials. The fifth factor was lack of vocabulary, decoding or word recognition. Students with no vocabulary won't be able to comprehend what they are reading and those who have problems in decoding and recognizing words will be reading slowly and find it challenging to understand the meaning of a text. Vocabulary can influence the reading comprehension skill because students utilize decoding skills to realize the meaning of new words. The sixth factor was the medical problems. According to An (2013) poor reading comprehension skill can be a medical difficulty that was not diagonized and addressed at an early age. Such as; lack of diagnoses of ADD (attention deficit disorder), dyslexia, speech problems, and hearing impairments can hinder the reading comprehension of students. The last factor was lack of parent involvement and lack of early sign language development. Learning a second language is said to be easier after mastering a first language. The lack of parent involvements in the education of their children affect the reading comprehension of students because they are not motivated from home, no one read for them because of a language barrier that may be between the deaf or hearing impaired students and the parents. Therefore, lack of SL at early age leads to students to become poor in vocabulary and be unable to read or comprehend passages. The findings showed that in learning a second language, in this case English, students clearly benefit from their earlier acquisition of SL, but this is difficult for HI students since they only come to acquire language when they come to school, meaning they start school with no language and begins to learn SL as a first languagesimultaneously with English as a second language.

\section{CONCLUSION AND SUGGESTION}

\section{Conclusion}

The of this study will be helpful to improve the reading comprehension of hearing impaired students. The first way of applying the knowledge will be the implementation of the researcher's learning, experiences and the research findings to the professional practice upon the return of the researcher in her home country.
Secondly, students will feel excited and motivated to read text with pictures and have Sign Exact English (SEE) books. Thirdly, teachers will be able to assist their students to improve their reading comprehension by using text with pictures or other effective teaching strategies for reading comprehension. Fourthly, the findings points to reading resources that will be needed to be redesigned accordingly by adding pictures to text and modify into SEE. Based on the findings, the learning strategies used for reading comprehension by hearing impaired include the text with pictures, use of visual aids, use of dictionary, signing while reading, the use of SEE books, finger spelling, re-reading and extracting new words from the text.

\section{Suggestion}

Based on the findings of this study, teachers are recommended to make use of text with pictures, there are other recommendations for English teachers teaching HI students. To develop their background knowledge by making use of visualization, making reading fun and interesting for students, teach text structures, and stimulate their reading ability. Teachers need to extract new vocabulary first from the text and discuss their meanings and signs then they can ask the students to read and later carry-out a reading comprehension test, they must use relevant text and suitable for the level of their students and also motivate students to read by making reading interesting and also they should teach their students how to use reading comprehension strategies appropriately and effectively. English teachers need to encourage their students to determine the factors that influence them to understanding what they are reading. Students have to be participating in the reading process by making use of different strategies to monitor their meaning.

\section{REFERENCES}

An, S. (2013). Schema theory in reading. Theory and Practice in Language Studies, 3(1), 130-134.

Andrews, J. F., \& Mason, J. M. (2011). Strategy usage among deaf and hearing readers. Exceptional Children, 57(6), 536-545.

Benedict, K. M., Rivera, M. C., \& Antia, S. D. (2015). Instruction in metacognitive strategies to increase deaf and hard-of-hearing students' reading comprehension. Journal of Deaf Studies and Deaf Education, 20(1), 1-15.

Bickham, L. M. (2015). Reading Comprehension in Deaf Education: Comprehension Strategies to Support Students Who are Deaf or Hard of Hearing. 
Creswell, J. W. (2013). Research design: Qualitative, quantitative, and mixed methods approaches. Sage publications.

Durkin, D. (2014). Teaching them to read (6 th ed) University of Florida, Pearson Education,Inc.

Evans, C., Zimmer, K., \& Murray, D. (2014). Discovering with words and signs: A resource guide for developing a bilingual and bicultural preschool program for deaf and hearing children. Sign Talk Development Project.

Gallaudet Research Institute. (2016). Stanford Achievement Test, 9th Edition, Form S, Norms Booklet for Deaf and Hard-of-Hearing Students. Washington, DC: Gallaudet University; http:/gri. gallaudet.edu/Literacy.

Hudson, R. F., Lane, H. B., \& Pullen, P. C. (2015). Reading fluency assessment and instruction: What, why, and how?. The Reading Teacher, 58(8), 702714.

Kamhi, A. G. \&, Catts, H. W. (2012). Language and reading disabilities (3 $\mathrm{rd}$ ed) Pearson Education, Inc. USA. Kelly, A. B. (1995). Fingerspelling interaction: A set of deaf parents and their deaf daughter. In C. Lucas (Ed.), Sociolinguistics in deaf communities (pp. 62-73). Washington, DC: Gallaudent University Press.
Lederberg, A. R., Schick, B., \& Spencer, P. E. (2013). Language and literacy development of deaf and hard-of-hearing children: successes and challenges. Developmental psychology, 49(1), 15.

Luckner, J. L. (2011). Mainstreaming Hearing-Impaired StudentsPerceptions of Regular Educators. Language, Speech, and Hearing Services in Schools, 22(1), 302-307.

Marschark, M., Sarchet, T., Convertino, C. M., Borgna, G., Morrison, C., \& Remelt, S. (2012). Print exposure, reading habits, and reading achievement among deaf and hearing college students. Journal of Deaf Studies and Deaf Education, 17(1), 61-74.

Mich, O.,Pianta, E.,\&, Mana, N. (2013). Interactive stories and exercises with dynamic feedback for improving reading comprehension skills in deaf children. Computers \& Education, 65(1), 34-44.

Oakhill, J. S., Scott, J. W., \& Kemp, B. E. (2009). Structure and function of AMP activated protein kinase. Acta physiologica, 196(1), 3-14.

Trussell, J. W., \& Easterbrooks, S. R. (2013). The effect of enhanced storybook interaction on signing deaf children's vocabulary. Journal of deaf studies and deaf education, 19(3), 319-332.

Vygotsky, L. (1978). Interaction between learning and development. Readings on the development of children, 23(3), 34-41. 